\title{
Odor Response Characteristics of Thalamic Mediodorsal Nucleus Neurons in the Rabbit
}

\author{
Kazuyuki Imamura, Norihiko ONODA, and Sadayuki F. TAKAGI \\ Department of Physiology, Gunma University School of Medicine, \\ Maebashi, Gunma, 371 Japan
}

\begin{abstract}
Extracellular responses were recorded from neurons in the thalamic mediodorsal nucleus (MD) of the lightly anesthetized rabbit. Eighty-seven neurons responded to electrical stimulation of the lateral olfactory tract (LOT shocks). They were located in the medial portion of the MD. In the same portion, negative field potentials with a short latency were evoked by the electrical stimulation of the olfactory projection area in the neocortex (OPA shocks). Fifty-nine MD neurons responded both to LOT and to OPA shocks. Among them, 17 thalamocortical relay neurons (which responded antidromically to OPA shocks) were found to respond transsynaptically to LOT shocks. Of the 87 LOT-responsive MD neurons, 48 responded to the odors applied. Eight odor-sensitive neurons were found to be the thalamocortical relay neurons. Thus, it was proven for the first time that a portion of the olfactory input to the OPA is mediated via relay neurons in the MD. Characteristics of response of MD neurons to odor stimulation were compared with those of OPA neurons. MD neurons did not show a selectivity of response to odors of urine, feces, or dry food pellets, to which OPA neurons responded exclusively. These results were discussed in relation to the functional role of the MD-OPA projection system in the discrimination of specific odors.
\end{abstract}

Key Words: mediodorsal nucleus, olfactory relay neuron, odor-responses.

Recent anatomical and electrophysiological studies have demonstrated projections from the piriform cortex, the olfactory tubercle, the endopiriform nucleus, and the amygdaloid nuclei to the medial portion of the mediodorsal nucleus (MD) of the thalamus (Heimer, 1972; LeOnard, 1972; KretteK and Price, 1974; BENJAMIN et al., 1982; BENJAMIN and JACKSON, 1974; JACKSON and BENJAMIN, 1974; Motokizawa, 1976). MD neurons in this portion send their axons to the prefrontal cortex (Tobias, 1975; TANAKA, 1976; KretTeK and Price, 1977;

Received for publication August 10, 1983

今村一之，小野田法彦，高木貞敬 
BenJamin et al., 1978; Divac et al., 1978; MARKOWITSCH et al., 1978, 1980; KOSMAL and DABRowSKA, 1980). In the anesthetized monkey, YARITA et al. (1980) found that MD neurons in the magnocellular portion were activated antidromically by stimulation of the centroposterior portion of the orbitofrontal cortex and transsynaptically by stimulation of the olfactory bulb (OB shocks). In addition, in the unanesthetized monkey, they reported that some MD neurons were activated by odor stimulation. However, the correlation between the responses of MD neurons to odor stimulation and those to the electrical stimulation of the OB or the orbitofrontal cortex has not been studied yet.

Regarding the role of a transthalamic olfactory pathway, recent behavioral studies have shown that lesions of the MD and/or sulcal cortex affect complex olfactory learning (SLOTNICK and KANEKO, 1981), odor guided behavior (EICHENBAum et al., 1980), and sexual behavior (SAPOLSKy and Eichenbaum, 1980). ONODA and IINO (1980) demonstrated electrophysiologically that over $60 \%$ of odor-sensitive neurons in the olfactory projection area of the rabbit prefrontal cortex (OPA) responded exclusively to odors of urine, feces, and dry food pellets. They thus suggested that OPA neurons play a central role in discrimination of specific odor patterns.

In a previous study (ONODA and IMAMURA, 1983), it was demonstrated that some of the OPA neurons received inputs from the MD in the rabbit; (1) electrical stimulation of the medial portion of the MD elicited field potentials in the OPA, (2) some odor-sensitive OPA neurons responded transsynaptically to MD shocks, and (3) after injection of horseradish peroxidase (HRP) into a small portion of the OPA, labeled cells were found predominantly in the medial segment of the MD. However, it remains unclear whether the selectivity of response to the specific odor patterns is inherent in OPA neurons, or whether such characteristics can also be found in the MD or lower olfactory structures.

The objective of this paper is (1) to examine the cortical projection of odorsensitive neurons in the MD, and (2) to compare the response characteristics to odors of OPA neurons with those of MD neurons.

The results are discussed in relation to the functional role of transthalamic olfactory input to the prefrontal cortex.

\section{METHODS}

Animal preparations. Twenty-four adult albino rabbits of both sexes, weighing $2.4-3.5 \mathrm{~kg}$, were used. As an initial step, a week before the experiments, a specially designed head attachment was fixed to the skull with stainless steel screws and dental cement under pentobarbital anesthesia. This attachment was used to immobilize the animal's head. The use of this attachment, instead of a conventional head holder, made it possible to leave a large space in front of the nose for odor application during recording sessions (ONODA and IINO, 1980; ONODA 
and MORI, 1980).

A week later, the animal was anesthetized again with pentobarbital sodium ( $35 \mathrm{mg} / \mathrm{kg}, \mathrm{i} . \mathrm{v}$.$) , and the trachea was cut. A glass cannula was inserted into$ the caudal end of the trachea for pulmonary ventilation. A postnasal cannula for artificial air-intake (AI) was inserted rostrally into the trachea through the larynx. The animal's head was fixed into a stereotaxic frame by the head attachment and an overhead bar. The cerebro-spinal fluid was drained off at the atlanto-occipital linkage to minimize pulsation of the brain. The right anterior frontal and parietal bone and dura were removed. The exposed brain was covered with a mixture of vaseline and mineral oil to prevent drying. Infiltration anesthetic (4\% Xylocaine) was applied around the skin incisions and subcutaneous wounded tissues. After these surgical procedures the animals were paralyzed by Br-pancuronium $(0.5-1.0 \mathrm{mg} /(\mathrm{kg} \cdot \mathrm{hr})$, i.v.) so that the possibility of recording neuronal discharges related to animal movement could be ruled out and that the air flow in the nasal cavity could be kept constant. Artificial ventilation was performed and the $P_{\mathrm{CO}_{2}}$ level in the expired air was continuously monitored and maintained between 3 and $4 \%$. EEG activity was monitored continuously. A small amount of Na-pentobarbital $(1-3 \mathrm{mg} /(\mathrm{kg} \cdot \mathrm{hr}))$ was applied periodically to keep the animals in a drowsy state. The body temperature was maintained at $38.5 \pm 0.5^{\circ} \mathrm{C}$ with a heating pad.

Electrical stimulation. Stainless steel acupuncture needles, insulated except for the tips, were used to stimulate the right LOT and the right OPA. A pair of such needles was fixed in parallel $0.5 \mathrm{~mm}$ apart, making a bipolar electrode. To verify that the tip of the stimulating electrode was in the LOT, the antidromically evoked field potentials in the ipsilateral olfactory bulb were monitored (MORI and TAKAGI, 1978). The electrodes used for stimulation of the OPA were fixed at a depth of $1.8 \mathrm{~mm}$ from the dorsal surface of the neocortex, $2.6 \mathrm{~mm}$ caudal to the frontal tip, and $2.5 \mathrm{~mm}$ lateral to the superior longitudinal sinus. This position was determined according to the locations of odor-sensitive neurons in the neocortex (ONODA and IINo et al., 1980). Electrodes were fixed to the skull with dental cement. Square pulses of $100 \mu \mathrm{A}$ and $20-50 \mu \mathrm{sec}$ were applied with electronic stimulators (MSE-3R, Nihon Kohden). With this stimulus intensity, the spread of effective current may be limited within an area of $1 \mathrm{~mm}$ radius surrounding the bipolar electrode (PORTER, 1963).

Odor stimulation. Animal products, dry food pellets for rabbit (Oriental Yeast Co., Chiba) and pure chemical substances were used as odorants. Odors of fresh animal products were obtained from (1) their own feces, (2) their own urine, (3) strange conspecific feces, and (4) strange conspecific urine. Pure chemicals were $d l$-camphor (CM), borneol (BL), cineol (CL), 1,2-dichloroethane (DE), methylcyclopentenolone (CLT), isovaleric acid (VA), isoamyl acetate (AA), and $\gamma$-undecalactone (UDL). These chemicals were diluted to a concentration of $10^{-2} \mathrm{v} / \mathrm{v} \%$ in an odorless mineral oil, Nujol (Plough, Inc., Memphis, Tenn.). 
All of the odorants were put into separate $30 \mathrm{ml}$ syringes. As a control, $200 \mu \mathrm{l}$ of Nujol was stored in another syringe. An odorous vapor was delivered to the animal's nostrils through Teflon tubes for 5-10 sec by pushing each plunger with a servomotor controlled by a pulse generator. The thirteen odors were applied in random order with inter-stimulus intervals of 1-3 min. Each odor was applied at least three times. A stream of air was passed through silica gel for dehydration and through activated charcoal for deodorization, and then through distilled water for the acquisition of adequate humidity. The air was allowed to flow at a constant rate of 4 liters $/ \mathrm{min}$. Intake of air into the nasal cavity was induced by applying negative pressure pulses to the postnasal cannula. The timecourse of the AI was monitored by a pressure transducer. In addition to odor stimuli, flashing light $(5 / \mathrm{sec})$, pure-tone pips ( 1 and $2 \mathrm{kHz}$ ), clap or whistle, and tactile (hair brush) and pinching stimuli to the vicinity of the nose and to the forelimbs were applied.

Recording procedures and data processing. Recordings of single units in the MD were made with glass micropipettes filled with $0.5 \mathrm{M}$ sodium acetate (10-30 $\mathrm{M} \Omega$ ) containing $2 \%$ brilliant blue. A silver plate indifferent electrode was placed under the neck muscles. Unit activities of MD neurons were amplified and displayed on an oscilloscope (Tektronix 5112) through a band-pass filter (300$3,000 \mathrm{~Hz}$ ). Unit activity, monitored outputs of AI cycles, and marks of odor application were registered on magnetic tape. A small computer (ATAC 450, Nihon Kohden) was used in constructing peri-stimulus time histograms (PSTHs) of unit activity and for statistical evaluation of the changes in the discharge rate on odor application, as follows.

Statistical evaluations of responses to odors (cf. IMAMURA and ONODA, 1983). Cumulative sum analysis and the Mann-Whitney $U$-test were carried out to evaluate responses to odors. In the cumulative sum analysis, consecutive numbers $\left(x_{1}, x_{2}, \cdots, x_{i}, \cdots\right)$ of spikes during the 20 -msec bin were measured for a total period of about $20 \mathrm{sec}(1,024$ addresses). Five hundred and twelve addresses were used to analyze the pre-stimulus events $\left(n_{1}\right)$. A cumulative sum chart (CSC) was constructed by plotting the $r$-th cumulative sum (cusum, $S r$ ) in order against each bin.

The $S r$ is given by:

$$
S r=\sum_{i=1}^{r}\left(x_{i}-\mu\right)
$$

$\mu$ : the mean number of spikes per bin in the pre-stimulus period. A marked characteristic of the CSC is that small changes in the firing rate can be displayed as a steep slope. In order to evaluate the changes in the discharge rate statistically, critical line $(K(i))$, which is given by the following equation, was calculated and depicted on the post-stimulus period of the CSC:

$$
K(i)= \pm 2.33 \sigma \sqrt{i-n_{1}},
$$


$\sigma:$ the standard deviation of spikes per bin in the pre-stimulus period. We judged that the discharge rate changed significantly $(p<0.01)$ when the cusum exceeded the critical line. The cusum analysis requires three statistical assumptions; namely, the spike number during each line $\left.\left(x_{i}\right) 1\right)$ is a random variable, 2) is independent statistically, and 3) has the same symmetrical distribution. The statistical precision of the cusum test was reduced when any of these assumptions was lacking. In that case, the Mann-Whitney $U$-test $(p<0.01)$ was carried out in spite of the defect showing neither temporal firing patterns nor occurrence points of changes. The responses reproducible more than three times were evaluated in this study. In the case of a unit lacking background activity, a reproducible response to an odor was used as a criterion.

Histological procedures. For identification of the unit location, a cathodal DC current (1-10 $\mu \mathrm{A}, 1-5 \mathrm{~min})$ was passed through the recording electrode after individual recordings. Under deep anesthesia, an anodal DC current (20 $\mu \mathrm{A}, 1 \mathrm{~min}$ ) was passed through stimulating electrodes (stainless steel) for histological checking of the sites of stimulation. The animal was then perfused transcardially first with a saline solution, then with buffered $10 \%$ formalin and $0.1 \%$ potassium ferrocyanide. Frontal or sagittal sections were made at $50 \mu \mathrm{m}$ and stained with thionine. Recording and stimulating points were reconstructed from marked brilliant blue spots and Prussian blue ones, respectively.

\section{RESULTS}

\section{Responses of MD neurons to LOT shocks}

Out of 538 neurons recorded in the MD, 87 neurons responded to LOT shocks. These neurons were located in the medial segment and the middle portion of the rostro-caudal extent of the MD. According to their patterns of response to LOT shocks, these MD neurons were classified into 6 types (types A-F). The response patterns did not change under the stimulating conditions described in MeTHODs. Each type of response is shown as peri-stimulus time histograms (PSTHs) in Fig. $1 \mathrm{~A}-\mathrm{F}$. In the cell shown in Fig. 1A, an LOT volley elicited discharges with two different latencies. The PSTH shows a first peak with a latency of $23 \mathrm{msec}$ and a second with one of $150 \mathrm{msec}$. Spike discharges disappeared for $94 \mathrm{msec}$ between the two peaks. The unit in Fig. 1B responded with a spike discharge at a short latency of $8 \mathrm{msec}$. The early activation was followed by a suppression for about $138 \mathrm{msec}$. The unit in Fig. 1C showed rebound facilitation after the suppression. The PSTH of the unit in Fig. 1D showed a large peak at $23 \mathrm{msec}$ and the discharge rate returned gradually to the background level. LOT shocks had no suppressive effect on this unit. In the cells shown in Fig. 1E and F, a suppression of spike discharges occurred for $158 \mathrm{msec}$ with a latency of $68 \mathrm{msec}$ and for $175 \mathrm{msec}$ with one of $88 \mathrm{msec}$ respectively, without the preceding early discharges. In the case of Fig. $1 \mathrm{~F}$, rebound activity followed.

Vol. 34, No. 1, 1984 


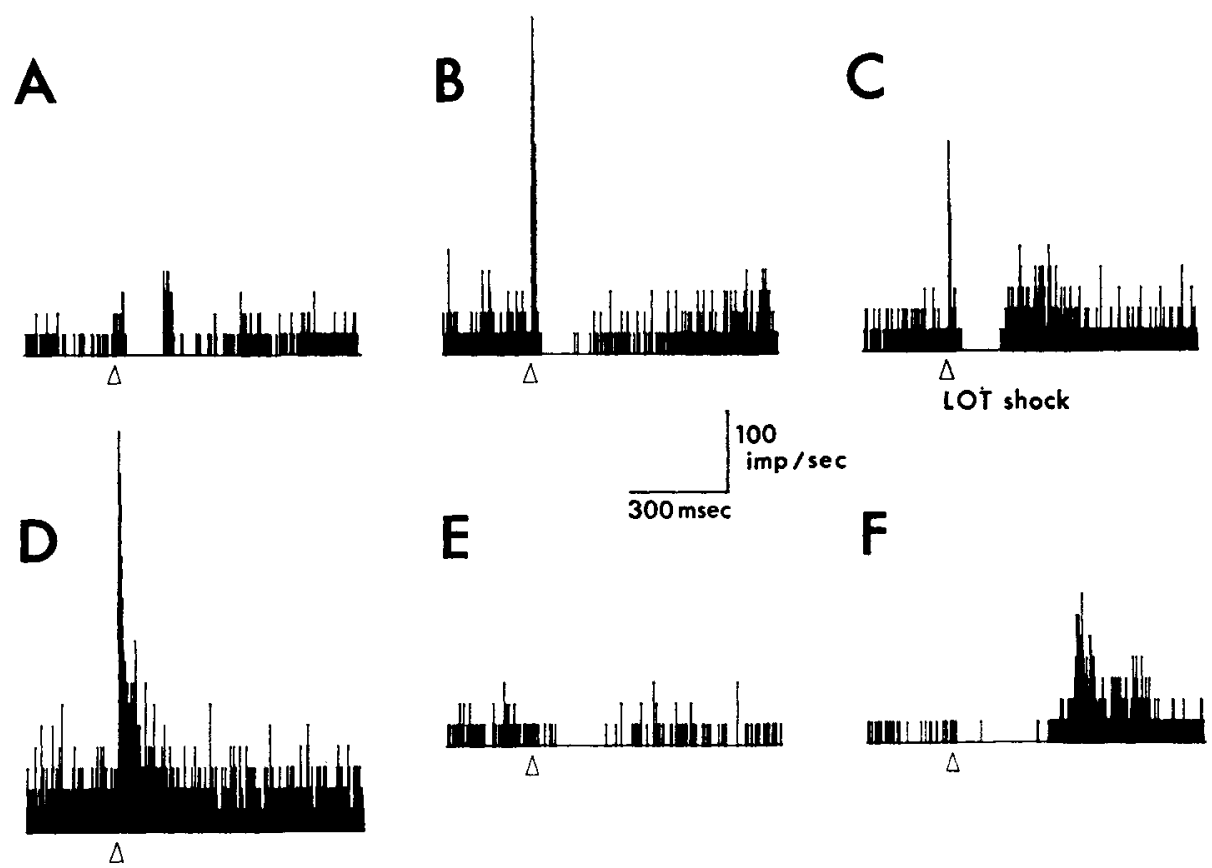

Fig. 1. Classification of single unit responses of MD neurons to LOT shocks. Each peristimulus time histogram (PSTH) was constructed from different units; 2-msec bin width, 512 addresses, 20 sweeps. Open triangles below the PSTHs indicate LOT shocks: $100 \mu \mathrm{A}$, $50 \mu \mathrm{sec}$ duration. Shock artifacts were removed by an inhibitor.

Table 1. The classification of responses of MD neurons to LOT shocks.

\begin{tabular}{|c|c|c|c|c|c|}
\hline $\begin{array}{l}\text { Unit } \\
\text { type }\end{array}$ & Response pattern & $\begin{array}{l}\text { Occurrence } \\
\text { of units }\end{array}$ & $\begin{array}{c}\text { Peak latency } \\
\text { of early } \\
\text { response } \\
\text { (msec)* }\end{array}$ & $\begin{array}{l}\text { Duration of } \\
\text { suppression } \\
\text { (msec)* }\end{array}$ & $\begin{array}{c}\text { Peak latency } \\
\text { of late } \\
\text { response } \\
\text { (msec)* }\end{array}$ \\
\hline A & Biphasic response & $10(11.5 \%)$ & $17.0 \pm 6.9$ & $125.7 \pm 56.7$ & $217.1 \pm 81.0$ \\
\hline B & $\begin{array}{l}\text { Phasic response follow- } \\
\text { ed by suppression }\end{array}$ & $6(6.9 \%)$ & $14.4 \pm 8.8$ & $175.4 \pm 95.6$ & \\
\hline $\mathrm{C}$ & $\begin{array}{l}\text { Phasic response follow- } \\
\text { ed by suppression with } \\
\text { rebound activity }\end{array}$ & $15(17.2 \%)$ & $14.8 \pm 8.4$ & $145.9 \pm 60.3$ & $350.5 \pm 98.0$ \\
\hline D 1 & Phasic response & $10(11.5 \%)$ & $16.3 \pm 16.8$ & & \\
\hline $\mathrm{E}$ & Suppressive response & $15(17.2 \%)$ & & $99.8 \pm 57.7$ & \\
\hline$F$ & $\begin{array}{l}\text { Suppressive response with } \\
\text { rebound activity }\end{array}$ & $31(35.6 \%)$ & & $148.5 \pm 59.1$ & $290.6 \pm 161.7$ \\
\hline & Total & \multicolumn{4}{|c|}{$87(100 \%)$ units } \\
\hline
\end{tabular}

* Mean \pm S.D.

According to differences in the latencies, the facilitatory responses were classified into three types: early discharges with latencies of less than $50 \mathrm{msec}$ 


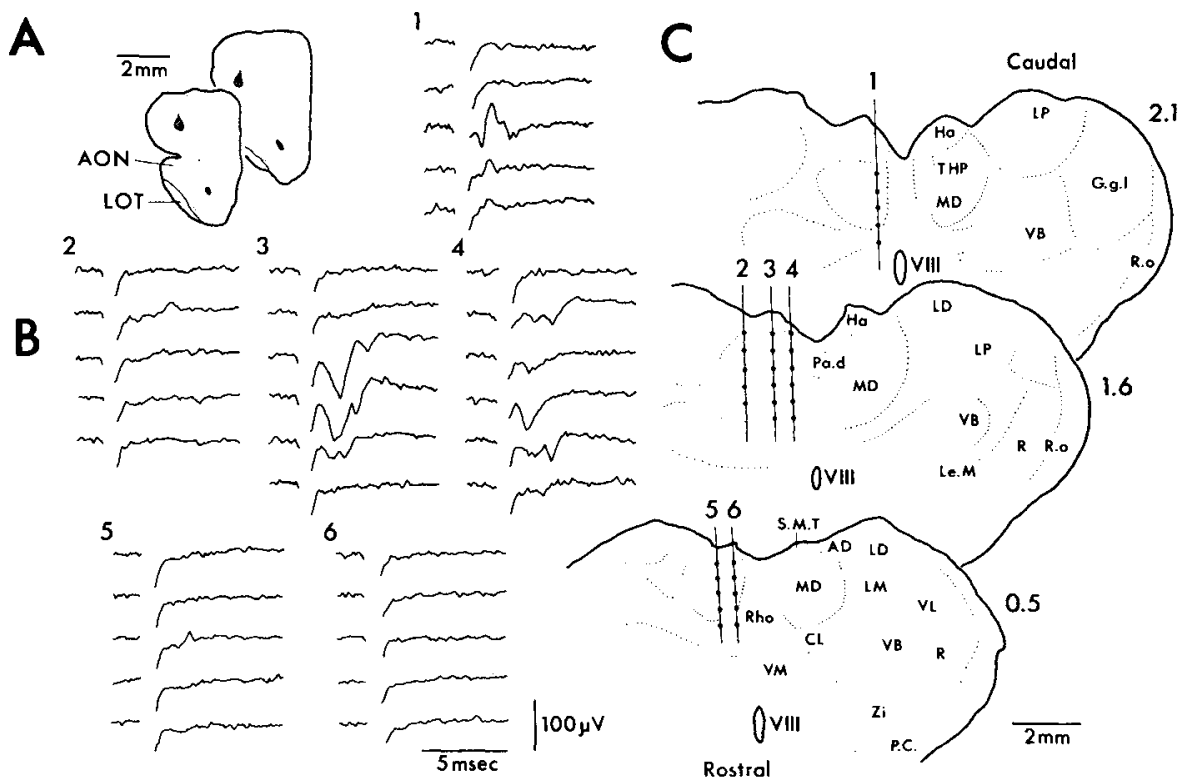

Fig. 2. OPA-evoked potentials at different recording points of the MD. A, stimulation points in the OPA. The two hatched areas indicate respectively the tips of bipolar stimulating electrodes. The two frontal sections were 1.95 and $2.70 \mathrm{~mm}$ caudal to the frontal pole, respectively. Dotted lines indicate borders between layer I and layer II in the cortex. B, depth profiles of summed evoked potentials $(20-\mu \mathrm{sec}$ bin width, 512 addresses, 20 shocks) recorded at the recording points indicated by dots on tracks 1 to 6 of C. Upward direction is electropositive. In each set of records, potentials obtained in the points most dorsal to the most ventral ones are shown from top to bottom. Numbers in B show track numbers in C. OPA shocks: $100 \mu \mathrm{A}, 20-\mu \mathrm{sec}$ duration. $\mathrm{C}$, electrode tracks and recording points reconstructed from frontal sections of dorsal thalamus. Numbers to the right of each section indicate the distance $(\mathrm{mm})$ from the rostral end of the MD. Anatomical abbreviations used in figures: AD, anterodorsal thalamic nucleus; $\mathrm{AON}$, anterior olfactory nucleus; $\mathrm{CL}$, centrolateral thalamic nucleus; G.g.1, lateral geniculate nucleus; Ha, habenular nucleus; LD, laterodorsal thalamic nucleus; Le.M, medial leminiscus; LM, lateral magnocellular thalamic nucleus; LOT, lateral olfactory tract; LP, lateroposterior thalamic nucleus; MD, mediodorsal thalamic nucleus; Pa.d, dorsal portion of paraventricular thalamic nucleus; P.C., cerebral peduncle; R, reticular thalamic nucleus; Rho, rhomboidal thalamic nucleus; R.o, optic radiation; S.M.T, stria medullaris; T.HP, habenulopeduncular tract; V III, third ventricle; VB, ventrobasal thalamic nucleus; VL, ventrolateral thalamic nucleus; VM, ventromedial thalamic nucleus; $\mathbf{Z i}$, zona incerta.

(Fig. 1B and D); late discharges with latencies of more than $100 \mathrm{msec}$ (Fig. 1F); dual early and late discharges (Fig. 1A and C). The interval between early and late discharges was characterized by an intermediate suppression.

Table 1 shows the number of neurons with six types of response patterns, the mean latencies of the early and late responses and the mean duration of suppres- 

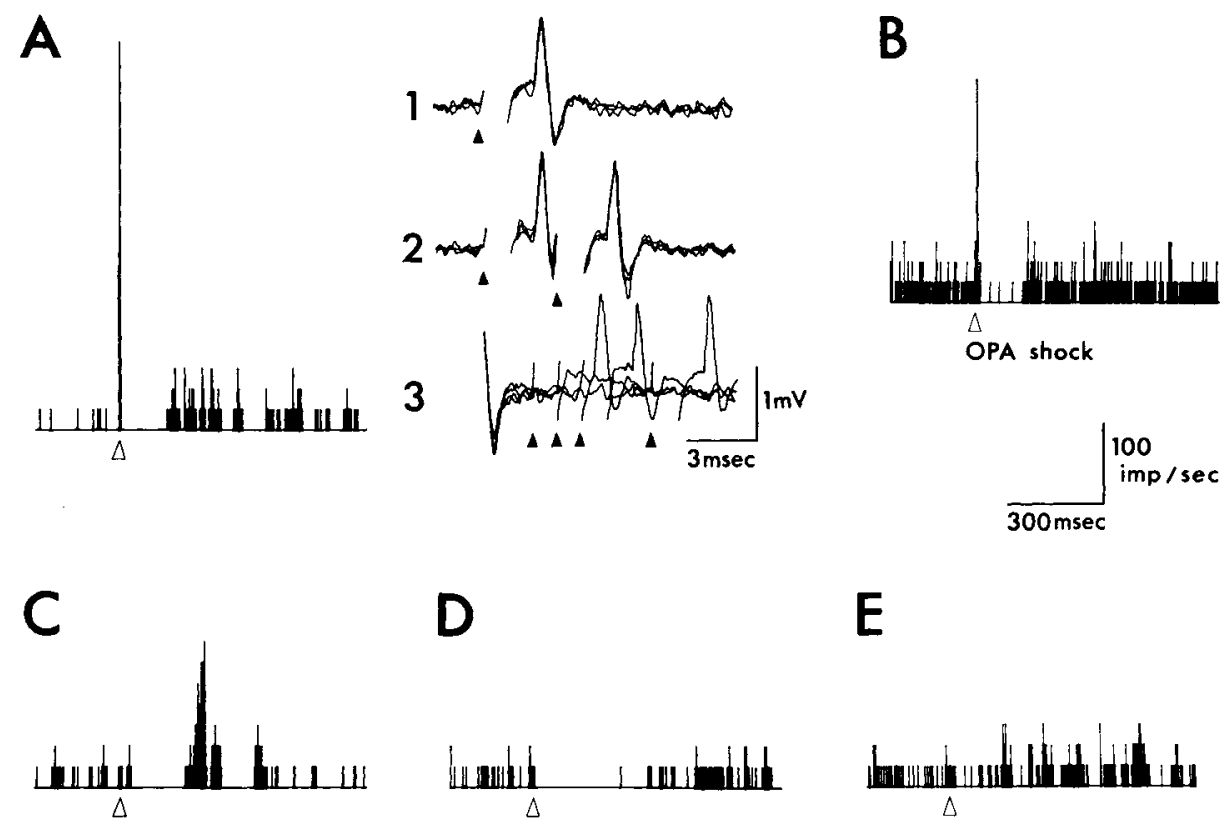

Fig. 3. Five different types of responses of MD neurons to OPA shocks. A to E show the responses of MD neurons as classified into five types. Open triangles below the PSTHs (2-msec bin width, 512 addresses, 20 sweeps) indicate OPA shocks (100 $\mu \mathrm{A}, 50$ - $\mu$ sec duration). A-1, three superimposed responses to single OPA shocks (closed triangle); A-2, three superimposed responses to double OPA shocks (3-msec intervals); A-3, result of a collision test. Closed triangles indicate the time of shocks applied. An initial rapid decay is a superimposed spontaneous discharge. The time interval between the initial spike and OPA shocks (closed triangle) was shortened and the collision time was measured.

sion. Unit types in Table 1 correspond to those in Fig. 1. The type F unit which showed a suppressive response followed by a rebound facilitation was most often observed. There was no significant difference in the peak latencies of the early responses among the four types of neurons (Table 1 A-D). The duration of suppression in the type $E$ neurons was significantly shorter than that in types $B$, $\mathrm{C}$, and $\mathrm{F}(t$-test, $p<0.05)$. The peak latency of the late response of the type $\mathrm{C}$ neurons was significantly longer than that of the type A neurons $(t$-test, $p<0.05)$.

\section{$O P A$-evoked potentials in the $M D$}

In three cases, we examined the depth distribution of OPA-evoked field potentials in the MD. OPA shocks induced a complex sequence of potentials in a restricted MD region (Fig. 2). The field potentials consisted of negative waves with peak latencies of less than $3 \mathrm{msec}$ and in some cases, they were followed by positive ones. The early negative waves were seen only in the $3 \mathrm{rd}$ and the 4 th traces 
Table 2. The classification of responses of MD neurons to OPA shocks.

\begin{tabular}{|c|c|c|c|c|c|}
\hline $\begin{array}{l}\text { Unit } \\
\text { type }\end{array}$ & Response pattern & $\begin{array}{l}\text { Occurrence } \\
\text { of units }\end{array}$ & $\begin{array}{l}\text { Peak latency } \\
\text { of early } \\
\text { response } \\
\text { (msec)* }\end{array}$ & $\begin{array}{l}\text { Duration of } \\
\text { suppression } \\
\text { (msec)* }\end{array}$ & $\begin{array}{l}\text { Peak latency } \\
\text { of late } \\
\text { response } \\
\text { (msec)* }\end{array}$ \\
\hline A & Antidromic response & $17(19.5 \%)$ & $2.6 \pm 1.1$ & $171.9 \pm 70.8$ & ** \\
\hline B & $\begin{array}{l}\text { Phasic response } \\
\text { (short latency) }\end{array}$ & $6(6.9 \%)$ & $7.7 \pm 4.4$ & $135.7 \pm 60.7$ & ** \\
\hline $\mathrm{C}$ & $\begin{array}{l}\text { Suppressive response } \\
\text { with synchronized } \\
\text { rebound activity }\end{array}$ & $16(18.4 \%)$ & & $116.8 \pm 30.2$ & $263.2 \pm 139.0^{* *}$ \\
\hline D & $\begin{array}{l}\text { Suppressive response } \\
\text { with unsynchronized } \\
\text { rebound activity }\end{array}$ & $13(14.9 \%)$ & & $198.8 \pm 88.0$ & ** \\
\hline \multirow[t]{4}{*}{ E } & Burst response & $7(8.0 \%)$ & & & ** \\
\hline & No response & $20(23.0 \%)$ & & & \\
\hline & Unchecked & $8(9.1 \%)$ & & & \\
\hline & Total & $87(100 \%) u$ & & & \\
\hline
\end{tabular}

* Mean \pm S.D. ** Burst rebound.

on track Nos. 3 and 4 (Fig. 2B). They followed high-frequency stimulation (more than $300 \mathrm{~Hz}$ ) and their peak latencies were fixed at $2.5 \mathrm{msec}$. Thus, the early negative waves seemed to be caused by antidromic activation of MD neurons which send their axons to the OPA. No potentials were recorded when recording points were shifted to the lateral (track 2) and to the rostral (tracks 5 and 6) regions. These results indicate that afferent fibers to the OPA originate in the medial segment and in the middle portion of the rostro-caudal extent of the MD.

\section{Responses of MD neurons to OPA shocks}

Of the MD units responding transsynaptically to LOT shocks, $74 \%$ responded also to OPA shocks. The responses were classified into 5 types according to their temporal firing patterns (types A-E). Typical examples are shown in Fig. 3AE. It was concluded that unit A in Fig. 3 was activated antidromically by OPA shocks, because (1) the spike response had a fixed latency (Fig. 3A-1), (2) it faithfully followed high-frequency stimulation (more than $300 \mathrm{~Hz}$, Fig. 3A-2), and (3) a collision test was passed (Fig. 3A-3). After the antidromic response with a short latency, its discharges disappeared for $146 \mathrm{msec}$ and subsequently bursts of rebound activity were seen. Unit B shown in Fig. 3 responded with a synaptically elicited discharge with a short latency (peak latency; $7.5 \mathrm{msec}$ ), and showed suppression of spike discharges for $150 \mathrm{msec}$ followed by bursts of rebound activity. When OPA shocks were applied, spike discharges of the two units $\mathrm{C}$ and $\mathrm{D}$ in Fig. 3 disappeared for 173 and $265 \mathrm{msec}$, respectively. In the unit in Fig. $3 \mathrm{C}$, bursts of rebound activity occurred at $248 \mathrm{msec}$ (1st-peak latency). From these results, suppressive responses followed by burst activities were supposed as being common response characteristics of MD neurons to OPA shocks. 

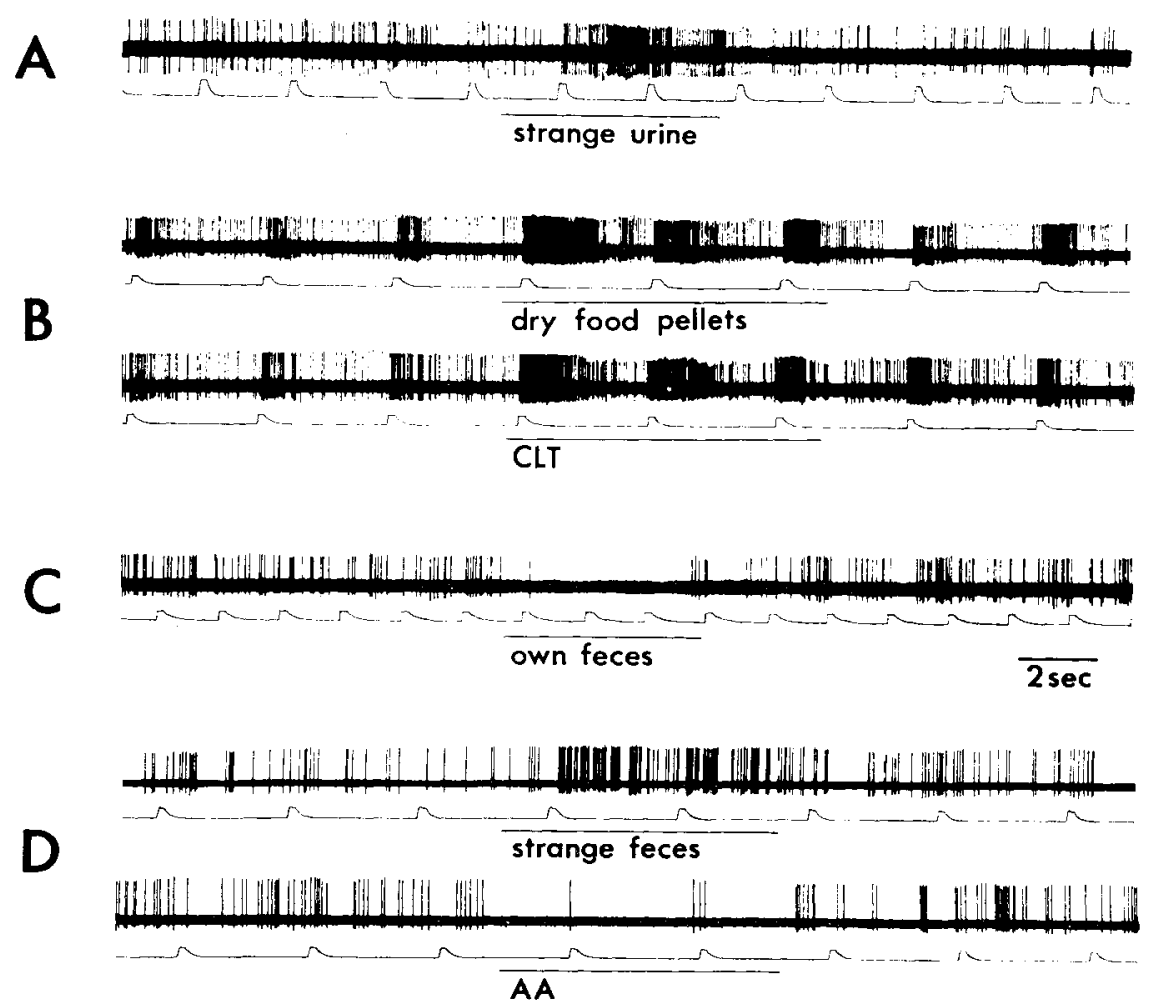

Fig. 4. Responses to odors of single MD units. In A to D, the spike activity of an MD unit is shown at the top. The record in the middle shows the AI cycles which were monitored by a pressure transducer. Upward direction is negative. The short horizontal bar at the bottom indicates the period of odor application. These three records compose a set. $A$ to $D$ are obtained from different neurons. A, a facilitatory response; $\mathrm{B}$, two facilitatory responses synchronized with $\mathrm{AI} ; \mathrm{C}$, an inhibitory response; D, a mixed response. "Strange" means conspecific rabbits. "Own" means the animal used in the experiment. Abbreviations: CLT, methylcyclopentenolone; AA, isoamyl acetate. The time scale is common to all records.

Another example of transsynaptic responses is shown in E. This unit showed neither initial facilitation nor subsequent suppression. Only burst discharges began, at $91 \mathrm{msec}$ after stimulation.

The number of neurons with the five types of response patterns are shown in Table 2, together with the peak latencies of the responses and the duration of suppression. Unit types in Table 2 correspond to those in Fig. 3. Out of 79, 29 units showed a suppressive response to OPA shocks. The suppressive period of type $\mathrm{C}$ was significantly shorter than that of types $\mathrm{A}$ and $\mathrm{D}$ ( $t$-test; $p<0.01$, $p<0.005)$. The peak latencies of antidromic responses were significantly shorter than those of phasic responses in the type B neurons $(t$-test, $p<0.0001)$. 

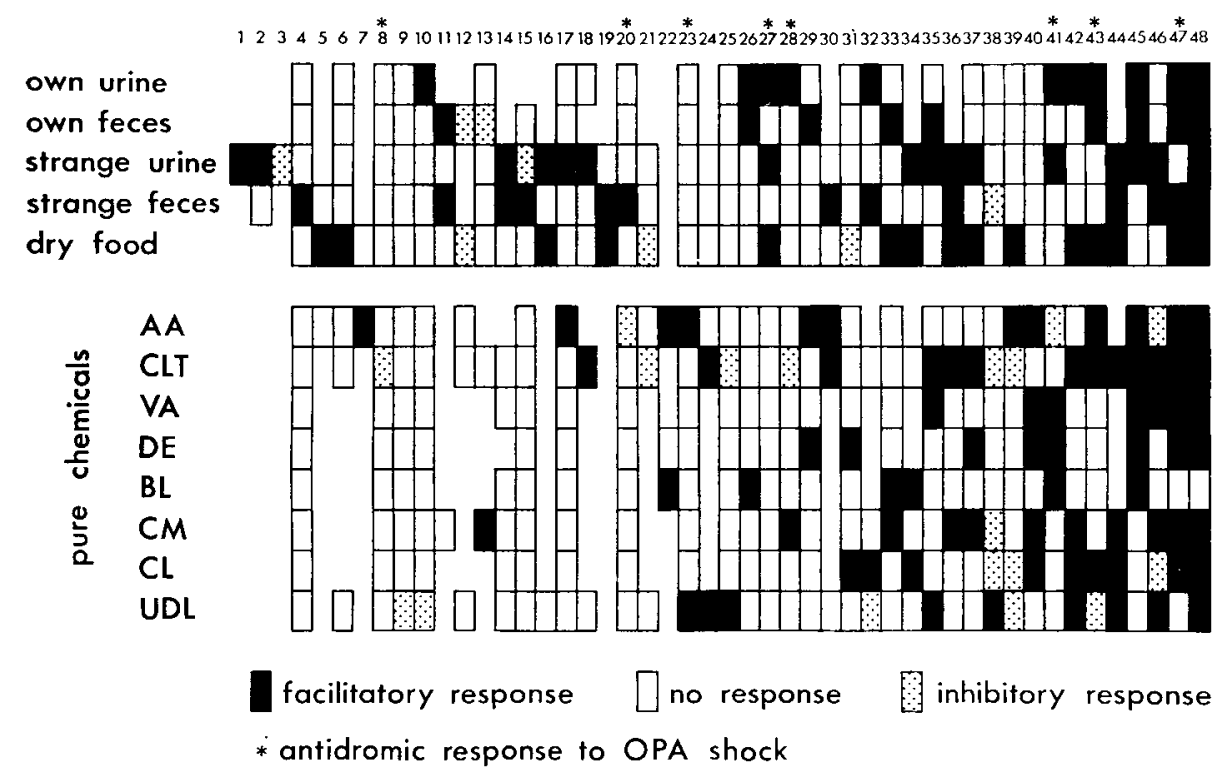

Fig. 5. A panel histogram of responses to odors obtained from 48 odor-sensitive MD neurons. Numbers over the histogram indicate the number of units recorded from. They are arranged in order of the number of odors responded to. * Thalamo-cortical relay neurons which responded antidromically to OPA shocks (see text). Abbreviations of odors shown in the extreme left are listed in METHODS.

\section{Responses of MD neurons to odor stimulation}

We studied responses to odors of $75 \mathrm{MD}$ neurons which responded to LOT shocks. MD neurons which showed no response to LOT shocks were not studied in this experiment. Forty-eight units responded to at least one odor examined. Four types of responses were observed. The typical responses are shown in Fig. 4A-D. In the absence of the odor stimulation, unit A showed an irregular background firing, whereas unit $\mathrm{B}$ fired in phase with AI cycles. The unit $\mathrm{A}$ increased its discharge rate (cusum test, $p<0.0001$ ) during odor stimulation with strange urine. The unit B showed a facilitatory response (Mann-Whitney $U$-test, $p<0.0001)$ to odors of dry food pellets and CLT. Unit C showed an inhibitory response (cusum test, $p<0.0001$ ) to the odor of own feces. Unit D showed a mixed response to odor stimulation: facilitation by the strange feces odor and suppression by the AA odor. The mixed response means that one neuron can show a facilitatory or inhibitory response according to the differences in the odors applied.

The results obtained from 48 units are summarized as a panel histogram in Fig. 5. The fact that eight of these units were activated antidromically to OPA shocks (indicated by a mark $*$ in Fig. 5) indicates that some MD neurons relay 

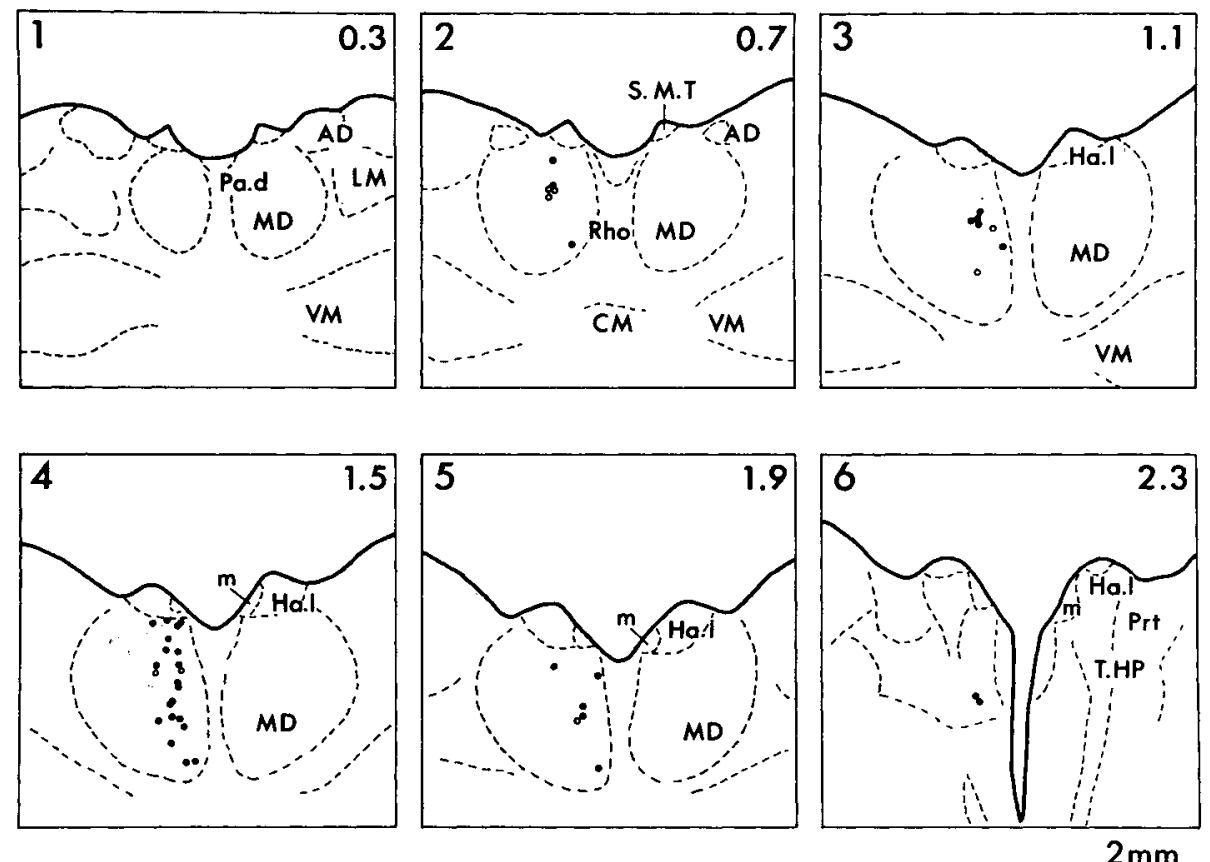

Fig. 6. Location of odor-sensitive MD neurons. Frontal sections from the dorsal thalamus are spaced at $400 \mu \mathrm{m}$ intervals. Numbers on the upper right indicate the distance (mm) from the rostral end of the MD. Filled circles and open circles indicate the sites of recording. Open circles show location of relay neurons which were activated antidromically by OPA shocks. Abbreviations: CM, centromedial thalamic nucleus; Ha. 1, lateral habenular nucleus; Ha.m, medial habenular nucleus; Prt, pretectal area. Other anatomical abbreviations are the same as shown in Fig. 2.

olfactory information to the OPA. It can be seen that 13 MD neurons $(27.1 \%)$ showed a facilitatory response. Thirteen other MD neurons showed a mixed response. Only two neurons $(4.2 \%)$ showed an inhibitory response. In the other 20 MD neurons, the type of response to odors could not be decided on. Response probabilities of neurons to each odor (the ratio of the number of units responding to the odor to the total number of units examined) varied from $19.35 \%(\mathrm{BL})$ to $46.2 \%$ (CLT). Neurons which fired in phase with AI cycles and responded to more than six odors (Nos. 42, 44, 45, 47, and 48) showed phasic response to LOT shocks (types A, B, C in Fig. 1) with short latencies ( $<10 \mathrm{msec})$. No other specific correlation was found between the patterns of response to odors and those to OPA or LOT shocks in this experiments on $48 \mathrm{MD}$ neurons. Unit Nos. 23 and 40 in Fig. 5 which were obtained from different animals were interesting, because they showed facilitatory responses not only to two and five odors respectively, but also to complex acoustic stimuli, such as whistle and clap. It 
should be noted that unit No. 23 has an olfactory input and sends its axon to the OPA. This indicates that some of the olfactory relay neurons in the MD are affected also by other sensory stimuli and send integrated information to the OPA. Unit No. 40 showed type $F$ in response to LOT shocks and type $C$ in response to OPA shocks. Other sensory stimuli had no effect on these two neurons.

\section{Localization of odor-sensitive units}

Locations of odor-sensitive units reconstructed from histological checks were plotted as dots on the frontal sections of the dorsal thalamus in Fig. 6. It can be seen that odor-sensitive MD neurons were distributed in the medial segment of the MD. Eighty-three percent of them were located in the middle portion of the MD rostro-caudally (1.0 to $2.0 \mathrm{~mm}$ caudal to the head of the MD). This portion corresponded to the region where OPA-evoked field potentials were obtained. We could not find any relationships between unit location and patterns of response to odors. The locations of unit Nos. 23 and 40 whose responses were mentioned above could not be segregated from those of other units.

\section{DISCUSSION}

Responses of MD neurons to LOT shocks. JACKSON and BENJAMIN (1974) analyzed the patterns of response of MD neurons to olfactory bulb (OB) stimulation in the rabbit. They classified the response patterns into three types: early discharges with latencies of $50 \mathrm{msec}$ or less, late discharges with latencies of more than 100 msec, and early discharges followed by late ones (both discharges). By means of PSTHs, the response patterns of MD neurons to the LOT stimulation were analyzed in the present study. The present results confirmed those of JACKSON and BENJAMIN (1974) and extended them in some aspects.

An LOT volley elicited early discharges in about $18 \%$, late discharges in about $36 \%$, and both discharges in about $29 \%$ of MD neurons, respectively. The latencies of the early discharges in the present study, which ranged from 2.8 to 45 msec, were shorter than those shown by JACKSON and BENJAMIN (1974), presumably due to the difference in the stimulation site (the $O B$ in their experiment and the LOT in our experiment). In a number of cases, the early discharges were followed by a prolonged suppression of the spike discharges. In the intracellular recordings from monkey MD neurons, YARITA et al. (1980) showed that OB stimulation elicited an early EPSP with spike discharges accompanied by a prolonged IPSP. It should be noted that in about $17 \%$ of MD neurons, LOT stimulation caused a prolonged suppression without the early and late discharges. The complex nature of the responses of MD neurons may reflect the complexity of the neuronal pathways from the LOT to the MD.

The MD neurons which responded to LOT shocks were located in the medial half of the nucleus. This is in agreement with the result of a previous study 
(JACKSON and BENJAMIN, 1974). In the present study, such neurons tend to be concentrated in the middle portion of the MD on the rostro-caudal axis.

Effect of OPA shocks on MD neurons. OPA shocks of small current (less than $100 \mu \mathrm{A}$ ) elicited a negative field potential in the MD. This was presumably caused by antidromic activation of MD neurons ( $c f$. Fig. 3A) in a restricted region of the MD nucleus. HRP-injection into the OPA resulted in a large number of retrogradely labeled neurons in this region of the MD (ONODA and IMAMURA, 1983). In addition, stimulation of this region elicited large potentials in the OPA (ONODA and IMAMURA, 1983). These results indicate that the neurons in this region send their axons to the OPA. The present study revealed that about $20 \%$ of MD neurons which responded to LOT shocks were activated antidromically by OPA shocks.

In addition to the projection from the MD nucleus to the OPA, anatomical studies have demonstrated that some neurons in the prefrontal cortex send their axons back to the MD (Siegel et al., 1977; TANaka, 1977; Price and SLOTNICK, 1983). In agreement with this, we also encountered 42 MD neurons which responded synaptically to OPA shocks. Forty of them also responded to both LOT shocks and odor stimulation. The above results indicate that OPAMD projections exist in the olfactory system. The cortico-thalamic system seems to play a role in the feedback control of olfactory inputs and regulate the response pattern of MD neurons to odors.

Odor responses of MD neurons. Although SAPAwI and DivaC (1978) stated that classical sensory inputs did not directly enter the MD, clear response selectivities and reproducible unit responses to odors found in this study can be interpreted as solid evidence for the existence of a direct effect of odors on the MD. Moreover, photic, acoustic, or somatic stimuli alone had no effect on odor-sensitive neurons excepting two cases only (which will be discussed below). The possibility that animal motion caused changes in the discharge rate could be ruled out because of the use of muscle relaxants, although it is still possible that motor command related impulses elicited the MD responses (GRIFFIN, 1970; WEST et al., 1979). Consequently, it can be said that at least some MD neurons are specifically related to odor information processing.

Although several studies have demonstrated the presence of inputs to the MD from the brain stem (VELAYOS and ReINOSO-SUAREZ, 1982) and from the auditory (Migliaro and D'ANNA, 1963), visual (MARKowitsch et al., 1982), and somatosensory systems (ENCABO and VoLKIND, 1968), only two odor-sensitive MD neurons were found in the present experiment which responded to whistling or clapping but not to pure tone ( 1 and $2 \mathrm{kHz}$ ), flash $(5 / \mathrm{sec})$, brushing, or pinching of the skin. The function of these MD neurons may be related to the interaction between the olfactory system and other sensory systems.

Correlation between patterns of response to electrical and odor stimulation.

MD neurons which responded to odor stimulation were classified into four types. 
One type of neuron showed characteristic burst discharges which appeared to be synchronous with the AI cycles. They always showed phasic early discharges with short latencies when LOT shocks were given. Neurons of this type responded to a number of different odors. These results suggest the existence of particular channels in the OB-MD pathway through which information of air flow or odor input in the nasal cavity are conveyed to the MD via relatively short synaptic chains.

In three other types of MD units, we were unable to find any correlation between patterns of response to electrical and odor stimulation.

Comparison of characteristics of response to odors between MD and OPA neurons. YARITA et al. (1980) showed responses to odors both in the centroposterior portion of the orbitofrontal cortex and in the MD of the monkey, but differences in characteristics of response to odors between the two structures have not been analyzed yet. Several behavioral studies have demonstrated that substructures in the thalamo-frontal pathway play a role in discriminative or cognitive aspects of processing biologically significant stimuli. In fact, ONODA and IINO (1980) demonstrated that OPA neurons respond selectively to biologically significant odors such as urine, feces, and dry food. The present results on the characteristics of response of MD neurons to odor stimulation were compared with those obtained on OPA neurons (Fig. 7). In the histograms of Fig. 7A, numbers of neurons, shown as percentages, were plotted against the number of odors responded to. Although TANABE et al. (1975) demonstrated that in the monkey the number of odors to which single cells responded declined along the olfactory pathway from the $\mathrm{OB}$ to the lateroposterior portion of the orbitofrontal cortex, rabbit OPA neurons did not show a tendency to respond to a smaller number of odors than the number of odors to which MD neurons responded.

In the histograms of Fig. 7B, numbers of neurons were plotted against facilitatory (F), inhibitory (I), and mixed (M) types of patterns of response to odor stimuli. Most of the OPA neurons (over $60 \%$ ) showed a facilitatory response, whereas most of the MD neurons showed either a facilitatory (46\%) or a mixed $(46 \%)$ response. This tendency was especially evident in non-relay MD neurons and OPA neurons which did not respond to MD shocks (white bars in Fig. 7B). With respect to the mixed responses of MD neurons, we could not find a fixed odor-pair, one of which always caused a facilitatory response when the other caused an inhibitory one.

In the histograms of Fig. $7 \mathrm{C}$, numbers of neurons were plotted against three groups of odors (A, P, and B): Over $60 \%$ of OPA neurons responded exclusively to the animal-product odors (A) which are closely related to chemical communication in the animal's life. No OPA neurons were found to respond exclusively to pure-chemical odors (P). Most (76\%) of the MD neurons, on the other hand, responded to both groups of odors (B). Neither olfactory relay neurons nor non-relay neurons in the MD showed a tendency to respond to biologically sig-

Vol. 34, No. 1, 1984 

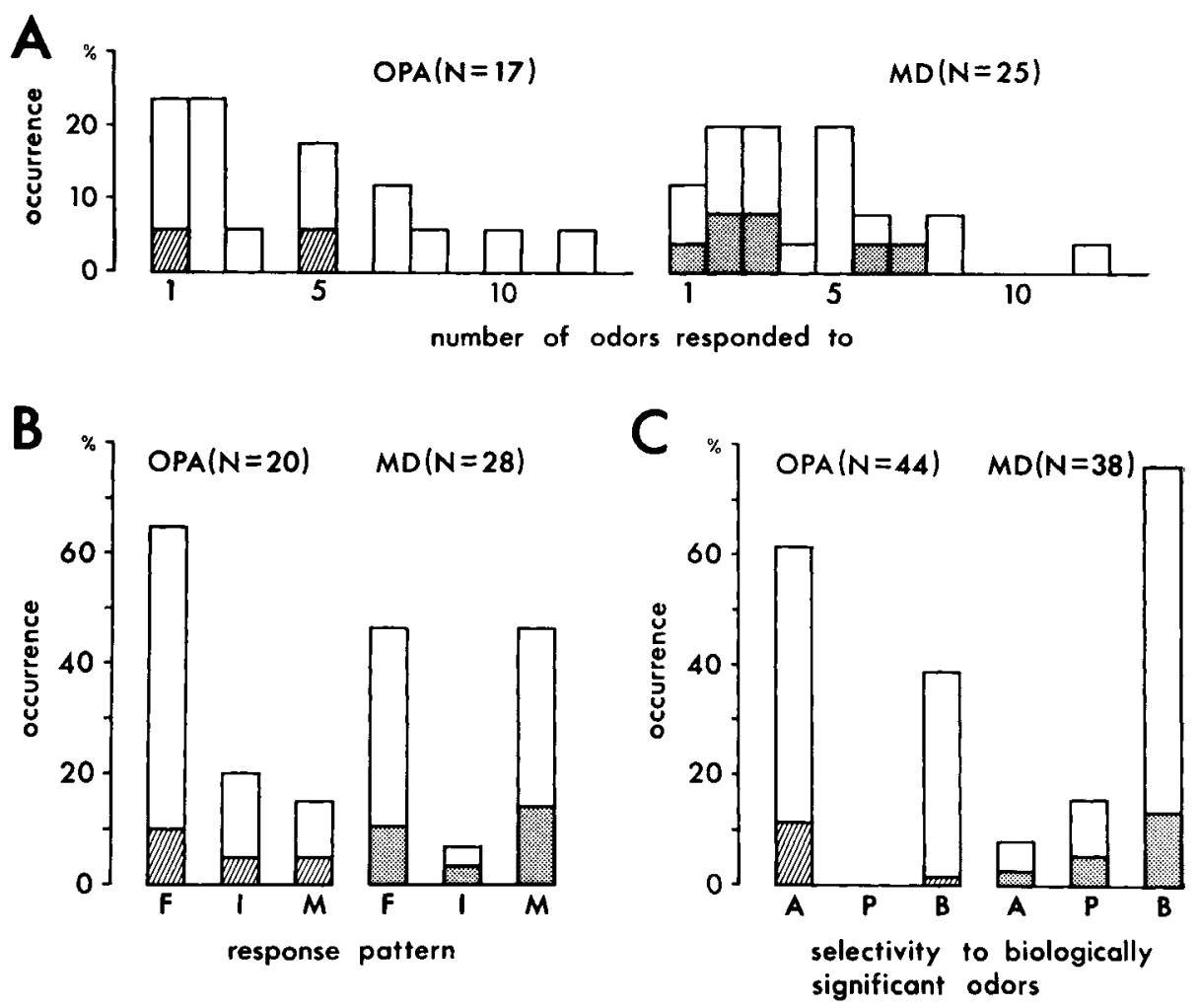

Fig. 7. Comparison of odor responses of OPA neurons with those of MD neurons. A: histograms show percentages of OPA and MD neurons which responded to one to twelve odors. B: histograms show three types of response to odors in OPA and MD. F, facilitatory type; I, inhibitory type; $\mathrm{M}$, mixed type. $\mathrm{C}$ : histograms show percentages of neurons responding to biologically significant and pure-chemical odors. A, units which responded exclusively to odors of animal products and/or dry-food pellets; $\mathrm{P}$, units which responded to odors of pure chemicals alone; $\mathbf{B}$, units which responded to both odor groups, $\mathbf{A}$ and $\mathbf{P}$. Striped and dotted bars indicate unit population which responded orthodromically to MD shocks and antidromically to OPA shocks, respectively.

nificant odors. The present results suggest, therefore, that the characteristic selective response of OPA neurons to biologically significant odors is not produced until olfactory inputs pass through the thalamo-cortical olfactory systems.

However, in the present experiment only a small number $(20 \%)$ of olfactory relay neurons were found in the MD. Essentially similar results were obtained in one of the previous studies (ONODA and IMAMURA, 1983) in that MD shocks elicited transsynaptic responses of less than $20 \%$ of odor-sensitive neurons in the OPA. The following reasons were considered for these facts: (1) In both experiments, electrical stimulation of only a small portion of the MD or OPA might not ac- 
tivate odor-sensitive neurons. (2) In both experiments, our selection of the quality and concentrations of stimulating odors might not be suitable to activate the thalamocortical relay neurons or OPA neurons which responded to MD shocks. (3) Olfactory afferents to the OPA other than those through the MD would also contribute to the activities of odor-sensitive neurons in the OPA. There exist direct projections to the OPA from the anterior olfactory nucleus (AON) and olfactory cortex in the rabbit (TAZAwA et al., 1982; ONODA and IMAMURA, 1983). With regard to the third possibility, further studies are needed to elucidate how significant the direct projections from the olfactory cortex to the OPA are.

The authors wish to thank Dr. K. Mori for his criticism of this manuscript and Mr. R. Cowan for revising the English expressions. They also thank Ms. T. Yajima for drawing the figures and Ms. T. Wada for typing the manuscript. This work was supported by a Grant-inAid for Scientific Research from the Ministry of Education, Science and Culture of Japan.

\section{REFERENCES}

Benjamin, R. M. and JACKson, J. C. (1974) Unit discharges in the mediodorsal nucleus of the squirrel monkey evoked by electrical stimulation of the olfactory bulb. Brain Res., 75: 181191.

Benjamin, R. M., JaCkson, J. C., and Golden, G. T. (1978) Cortical projections of the thalamic mediodorsal nucleus in the rabbit. Brain Res., 141: 251-265.

Benjamin, R. M., Jackson, J. C., Golden, G. T., and West, C. H. K. (1982) Sources of olfactory inputs to opossum mediodorsal nucleus identified by horseradish peroxidase and autoradiographic methods. J. Comp. Neurol., 207: 358-368.

Divac, I., Buörklund, A., Lindvall, O., and Passingham, R. E. (1978) Converging projections from the mediodorsal thalamic nucleus and mesencephalic dopaminergic neurons to the neocortex in three species. J. Comp. Neurol, 180: 59-72.

Eichenbaum, H., Shedlack, K. J., and EckmanN, K. W. (1980) Thalamocortical mechanisms in odor-guided behavior. I. Effects of lesions of the mediodorsal thalamic nucleus and frontal cortex on olfactory discrimination in the rat. Brain Behav. Evol., 17: 255-275.

ENCABO, H. and VolKIND, R. (1968) Evoked somatic activity in nucleus medialis dorsalis: A micro-electrode study. Electroencephalogr. Clin. Neurophysiol., 25 : 252-258.

Griffin, J. P. (1970) The effects of lesions of the dorsomedial nucleus of the thalamus upon habituation of the flexor reflex response in the rat. Brain Res., 19: 421-426.

Heimer, L. (1972) The olfactory connections of the diencephalon in the rat. Brain Behav. Evol., 6: 484-523.

ImAMURA, K. and OnODA, N. (1983) The cumulative sum analysis of spike discharges in a small sample. Jpn. J. Physiol, 33: 135-138.

JACKson, J. C. and Benjamin, R. M. (1974) Unit discharges in the mediodorsal nucleus of the rabbit evoked by electrical stimulation of the olfactory bulb. Brain Res., 75: 193-201.

Kosmal, A. and Dabrowska, J. (1980) Subcortical connections of the prefrontal cortex in dogs: Afferents to the orbital gyrus. Acta Neurobiol. Exp. (Warsz.), 40: 593-608.

Krettek, J. E. and Price, J. L. (1974) A direct input from the amygdala to the thalamus and the cerebral cortex. Brain Res., 67: 169-174.

Krettek, J. E. and PrICE, J. L. (1977) The cortical projections of mediodorsal nucleus and adjacent thalamic nuclei in the rat. J. Comp. Neurol., 171: 157-192. 
LEONARD, C. M. (1972) The connections of the dorsomedial nuclei. Brain Behav. Evol., 6: $524-541$.

Markowitsch, H. J., Irle, E., and Streicher, M. (1982) The thalamic mediodorsal nucleus receives input from thalamic and cortical regions related to vision. Neurosci. Lett., 32: 131136.

Markowitsch, H. J., Pritzel, M., and Divac, I. (1978) The prefrontal cortex of the cat: Anatomical subdivisions based on retrograde labeling of cells in the mediodorsal thalamic nucleus. Exp. Brain Res., 32: 335-344.

Markowitsch, H. J., Pritzel, M., Wilson, M., and Divac, I. (1980) The prefrontal cortex of a prosimian (Galago senegalesis) defined as the cortical projection area of the thalamic mediodorsal nucleus. Neuroscience, 5: 1771-1779.

Migliaro, E. F. and D'AnNA, L. (1963) Interaction between visual and auditory responses in the cortex and the thalamus of the cat under chloralose anaesthesia. Acta Physiol. Lat. Am., 13: 242-254.

MoRI, K. and TAKAGI, S. F. (1978) An intracellular study of dendrodendritic inhibitory synapses on mitral cells in the rabbit olfactory bulb. J. Physiol. (Lond.), 279: 569-588.

Motokizawa, F. (1976) Higher olfactory projections. In: Electrobiology of Nerve, Synapse, and Muscle, ed. by Reuben, J. P., Purpura, D. P., Bennett, M. V. L., and Kandel, E. R. Raven Press, New York, pp. 235-242.

ONODA, N. and Ino, M. (1980) Selective responses to odors of animal products in the neocortex neurons of rabbits. Proc. Jpn. Acad., 56: 300-305.

ONoDA, N. and Imamura, K. (1983) Selective responses to animal-product odors in the neocortical neurons. Soc. Neurosci. Abstr., 9: 465.

ONODA, N. and MoRI, K. (1980) Depth distribution of temporal firing patterns in olfactory bulb related to air-intake cycles. J. Neurophysiol., 44: 29-39.

PORTER, R. (1963) Focal stimulation of hypoglossal neurons in the cat. J. Physiol. (Lond.), 169: $630-640$.

Price, J. L. and Slotnick, B. M. (1983) Dual olfactory representation in the rat thalamus: An anatomical and electrophysiological study. J. Comp. Neurol., 215: 63-77.

SAPAWI, R. R. and Drvac, I. (1978) Connections of the mediodorsal nucleus of the thalamus in the tree shrew. I. Afferent connections. Neurosci. Lett., 7: 183-189.

SAPOLSKY, R. M. and EICHENBAUM, H. (1980) Thalamocortical mechanisms in odor-guided behavior. II. Effects of lesions of the mediodorsal thalamic nucleus and frontal cortex on odor preferences and sexual behavior in the hamster. Brain Behav. Evol., 17: 276-290.

Siegel, A., Fukushima, T., Meibach, R., Burke, L., Edinger, H., and Weiner, S. (1977) The origin of the afferent supply to the mediodorsal thalamic nucleus: Enhancement of HRP transport by selective lesions. Brain Res., 135: 11-23.

Slotnick, B. M. and KANEKo, N. (1981) Role of mediodorsal thalamic nucleus in olfactory discrimination learning in rat. Science, 214: 91-92.

TANABE, T., IINo, M., and TAKagi, S. F. (1975) Discrimination of odors in olfactory bulb, piriform-amygdaloid areas, and orbitofrontal cortex of the monkey. J. Neurophysiol., 38: 12841296.

TANAKA, D., Jr. (1976) Thalamic projections of the dorsomedial prefrontal cortex in the rhesus monkey (Macaca mulatta). Brain Res., 110: 21-38.

TANAKA, D., Jr. (1977) Projections from orbitofrontal cortex to mediodorsal thalamic nucleus in the dog. Brain Res., 131: 356-361.

Tazawa, Y., Mori, K., and TAKagi, S. F. (1982) The dendritic and axonal projection patterns of the neurons in the rabbit anterior olfactory nucleus: Intracellular HRP staining. Neurosci. Lett. (Suppl.), 9: S119.

Tobias, T. J. (1975) Afferents to prefrontal cortex from the thalamic mediodorsal nucleus in the 
rhesus monkey. Brain Res., 83: 191-212.

Velayos, J. L. and Reinoso-SuAREZ, F. (1982) Topographic organization of the brainstem afferents to the mediodorsal thalamic nucleus. J. Comp. Neurol., 206: 17-27.

West, C. H. K., JACKson, J. C., and Benjamin, R. M. (1979) An autoradiographic study of subcortical forebrain projections from mediodorsal and adjacent midline thalamic nuclei in the rabbit. Neuroscience, $4: 1977-1988$.

Yarita, H., Iino, M., Tanabe, T., Kogure, S., and Takagi, S. F. (1980) A transthalamic olfactory pathway to orbitofrontal cortex in the monkey. J. Neurophysiol., 43: 69-85. 